\title{
EFFECT OF HIGH TEMPERATURE ON THE MECHANICAL STRENGTH OF RUBBERIZED CONCRETE MORTAR
}

\author{
M. H. Seleem, M. M. Balaha, H. S. Khalil, E. Zaki \\ Engineering Materials Department, Faculty of Engineering, Zagazig University, Egypt
}

\begin{abstract}
The development of environmentally accepted metbods of used tire disposal is one of the greatest challenges that waste management experts face today. When building materials are subjected to fire and exposed to cooling, some changes may occur in their characteristics; such as phase transformation, weight loss, aggregate-cement bond, etc., which directly affects on its chemical stability and mechanical properties. In the present investigation, the effect of high temperature of the compressive and tensile strengths of concrete mortar fabricated from ground waste tire rubber (GWTR) as a partial replacement of total fine aggregate (TFA), sand, was experimentally investigated. The percentages by volume of GWTR/TFA were, $0 \%, 5 \%, 10 \%, 15 \%$ and $20 \%$. All mortar samples were prepared and cured using tap water for 28 days, then kept in laboratory atmosphere until the beginning of the test. The specimens were subjected to different target: temperatures of $100,200,300,400$ and $500^{\circ} \mathrm{C}$. After reaching to the desired target temperature, the specimens were sustained at desired temperature for 2 hours. After heating the specimens were allowed to cool at room temperature until the date of the test. The test results showed that all mortar specimens exposed to high temperature suffered a significant decrease in both compressive and tensile strengths. Replacing sand by $5 \% 10 \%$ GWTR recorded the highest relative compressive strength, while replacing sand by 10-15\% GWTR recorded the highest relative tensile strength compared with other replacement ratios. The mass loss increased with increasing of temperature up to $500^{\circ} \mathrm{C}$ and GWTR \%. In addition, at high temperature $500^{\circ} \mathrm{C}$ it was noticed that no cracks appeared on the surface of specimens.
\end{abstract}

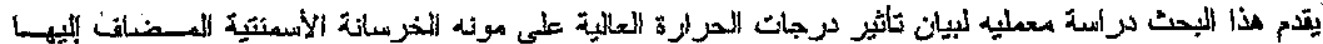

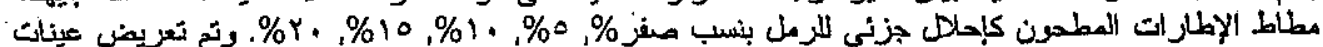

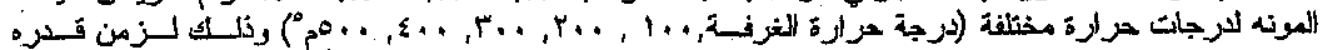

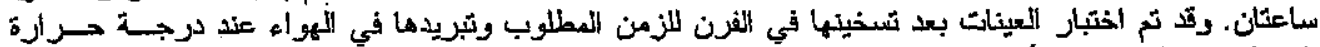

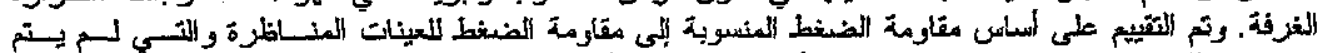

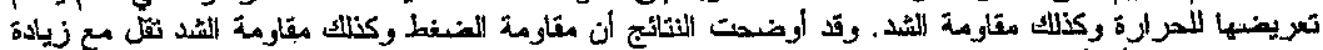

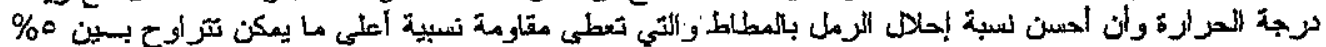

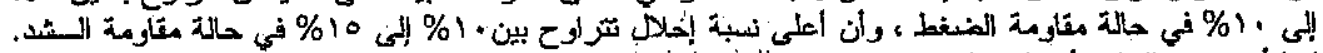

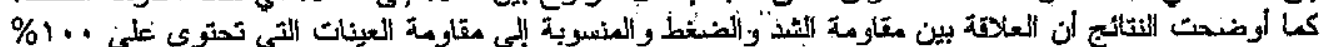

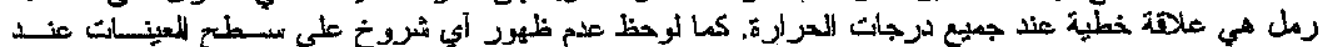

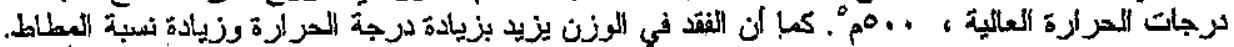

Keywords: Ground tire rubber; Mortar; High Temperature; Compressive strength; Tensile strength.

\section{INTRODUCTION}

Waste tires pose a health hazard since tire piles are excellent breeding grounds for mosquitoes. Because of the shape and impermeability of tires, they may hold water for long periods providing sites for mosquito larvae development. Waste tires also pose a serious fire hazard since wáste tires and waste tire stockpiles are difficult to ignite. However, once ignited tires burn very hot and are very difficult to extinguish. A large tire fire can smolder for several weeks or even months, sometimes with dramatic effect on the surrounding environment. An end-oflife tire is a used tire that cannot or is not reused for its originally intended purpose and is not retreated. Such tires may have a further use as a raw material for other processes or be destined for final disposal. End-of-life tires are called "scrap tires" in the United States [1]. However, all of the recycling re-uses and recovery practices combined only consume about $22 \%$ of the discarded tires. Thus, a need still exists for the development of additional uses for scrap tires $[2-4]$. Nowadays, waste tire disposal is a significant 
problem and finding an environment friendly and potentially attractive method is the greatest challenge. The difficulty in the recycling of the waste tire is that the tire rubber is a cross linked polymer that is hard to melt and to process [5-6].

Utilization of waste tires would eliminate castle pollution that is required to prevent degradation of air, land and water in the vicinity of the waste disposal sites. Also buming the remains tires rubber for getting rid of them causes a very big pollution to the environrnent. Therefore, many studies [7-9] were directed to avoid the problems due to burn the remains tires rubber and studying the role of utilization the ground waste tires rubber as aggregates in concrete. Many properties of the concrete can be improved being used the tire chips in c.ivil engineering applications such as low material density, high bulk permeability, high thermal insulation, high durability: and high bulk compressibility. On heating, a neat Portland cement paste first expands owing to its normal thermal expansion. This expansion, however, is exposed to a contraction due to the shrinkage of the material as water is driven off from it. The contraction due to drying eventually becomes much larger than its normal thermal expansion and the material then begins to shrink. The temperature at which the maximum shrinkage is reached varies with the size of the specimen and the conditions of heating. It may be as high as $300^{\circ} \mathrm{C}$ for air-dry specimens under conditions of fairly rapid heating. At more temperatures the neat cement steadily shrinks, the contraction from the original dimensions amounting ultimately about 0.5 percent or more. During this process, severe cracking occurs [10]. Hydrated Portiand cement contains a considerable proportion of free calcium hydroxide, which loses its water above $400-500^{\circ} \mathrm{C}$, leaving calcium oxide (quick lime). If $\mathrm{CaO}$ becomes wetted after cooling as exposed to moist air, it rehydrates to $\mathrm{Ca}(\mathrm{OH})_{2}$ accompanied by an expansion in volume that may disrupt a concrete, which has withstood a fire without disintegration [11].

The best fire resistant aggregate, which is characterized by a very fine crystalline texture or a non-crystalline basic material such as limestone, expands steadily until a temperature of about $900^{\circ} \mathrm{C}$ is reached, then begins to contract owing to decomposition of $\mathrm{CaCO}_{3}$ with liberation of $\mathrm{CO}_{2}$. It has often been considered, on account of this decomposition, that the concrete with limestone has no fire resistance beyond this temperature [12]. Long series of tests on the fire resistance of structures have been carried out in Britain and USA. All concretes, which are considered the most fire resistant, attained a serious reduction in strength at a temperature above $600^{\circ} \mathrm{C}$ and fail if exposed for a considerable time to a temperature exceeding $900^{\circ} \mathrm{C}$ [13]. However, regardless the different nature, size and composition of used tire rubbers, a meaningful decrease in concrete compressive strength with the increasing amount of rubber phase in the mixture was always detected [14]. It was found that the damping ratio of rubberized concrete containing $20 \%$ rubber is much higher than that of traditional concrete by about $63.2 \%$

In the present investigation ground waste tires rubber was used as a partial replacement for fine aggregates by volume $(0 \%, 5 \%, 10 \%, 15 \%$ and $20 \%)$. All mortars samples were exposed to five different temperatures $100,200,300,400$ and $500^{\circ} \mathrm{C}$ for 2 hours soaking time with heating rate of $10-20^{\circ} \mathrm{C}$. The weight loss and residual compressive and tensile strengths due to exposure to those high temperatures were experimentally investigated in the present paper.

\section{EXPERIMENTAL PROGRAMME}

The cement used in mortar mixes was ordinary Portland cement (OPC) from Suez Cement Company. The properties of the used cement are given in Table 1. The used sand was siliceous sand with $100 \%$ passing ASTM sieve No. 4 with a fineness modulus of 2.75 . The cement content was $400 \mathrm{~kg} / \mathrm{m}^{3}$. The sand to cement ratio was equal to $3: 1$. The used ground waste tire rubber (GWTR) in this research was produced by (El-Nasr Tire Company) by grinding the waste tires with special technique. The total fine aggregates (TFA) in all mixes were sand partially replaced by fine GWT'R particles. The percentages by volume of GWTR/TFA were $0 \%, 5 \%$, $10 \%, 15 \%$ and $20 \%$. Sieve analysis of the used GWTR and sand are given in Table 2: The physical properties of the used fine GWTR are given in Table 3. Cubes $70 \times 70 \times 70 \mathrm{mms}$ were prepared for testing under static compressive loadings. Cylinders of $75 \mathrm{mms}$ diameter and $150 \mathrm{mms}$ height were prepared for testing under indirect tension test. The mortar constituent materials were batched separately by weight. Mixing was performed in a small rotatingdrum mixer. First, cement and waste tire nbber were dry mixed until a homogeneous mix was observed before mixing the sand to it, and then water was gradually added while mixing continued for about five minutes. All specimens were cast in steel molds, then demolded after 24 hours ancl cured in fresh water for 28 days. All specimens were cast and treated under the same environmental conditions.

After curing, the specimens were exposed to temperatures of $100,200,300,400$ and $500^{\circ} \mathrm{C}$ and kept at that temperature for 2 hours in semi-open muffle furnace with an average heating rate of $10^{\circ} \mathrm{C}$ per minute. After heating, the specimens were left to cool in air until the time of testing. The compressive 
and indirect tensile tests were carried out in a hydraulic universal testing machine of $1000 \mathrm{kN}$ capacity.

Table 1 Properties of the used OPC

\begin{tabular}{|l|c|c|}
\hline \multicolumn{1}{|c|}{ Property } & Results & $\begin{array}{c}\text { B.S. } \\
\text { Limits }\end{array}$ \\
\hline Initial setting time & $1.45 \mathrm{hr}$ & $\geq 45 \mathrm{~min}$ \\
\hline Final setting time & $4.25 \mathrm{hr}$ & $\leq 10 \mathrm{hr}$ \\
\hline Fineness, $\mu \mathrm{m}$ & 8 & $\leq 10$ \\
\hline Compressive strength & & \\
$\left(\mathrm{kg} / \mathrm{cm}^{2}\right)$ & & \\
After 3 days & 225 & $\geq 160$ \\
After 7 days & 297 & $\geq 240$ \\
After 28 days & 379 & $\geq 360$ \\
\hline
\end{tabular}

Table 2 Sieve analysis of GWTR and sand.

\begin{tabular}{|c|c|c|}
\hline \multirow{2}{*}{ Sieve Opening, mm } & \multicolumn{2}{|c|}{ \% passing } \\
\cline { 2 - 3 } & GWTR & Sand \\
\hline 5 & 100 & 100 \\
\hline 2.5 & 100 & 97.8 \\
\hline 1.25 & 13.4 & 84.9 \\
\hline 0.62 & 3.8 & 58.4 \\
\hline 0.31 & 1.6 & 8 \\
\hline 0.16 & 0.6 & 2.2 \\
\hline
\end{tabular}

Table 3 Physical properties of GWTR.

\begin{tabular}{|l|c|c|}
\hline \multicolumn{1}{|c|}{ Property } & GWTR & Sand \\
\hline Specific gravity & 0.9 & 2.45 \\
\hline Unit weight g/cm & 0.67 & 1.7 \\
\hline Absorption \% & 1.9 & 0.42 \\
\hline Fineness Modulus & 3.81 & 2.45 \\
\hline
\end{tabular}

\section{RESULTS AND DISCUSSIONS}

\subsection{Compressive Strength}

The effect of high temperatures on the relative compressive strength of mortar specimens fabricated by partial replacement of sand by GWTR (GWTR/TFA \% $=0,5,10,15$ and $20 \%$ ) is shown in Fig. 1. The relative compressive strength showed in the figure is ratio multiplied by 100 of the strength of specimen exposed to high temperature to that of the unheated specimen at the same GWTR/TFA \%. It is clear that, all mortar mixes exposed to fire suffered a significant depression in compressive strength.

The average relative compressive strength for all GWTR/TFA \% was about $93,90,83,75$ and $56 \%$ for target temperatures of respectively $100,200,300$, 400 and $500^{\circ} \mathrm{C}$. The small gradual decrease in the compressive strength at low temperature may be due to the existence of rubber particles absorbs the volume change occurred in the specimens due to heating. At high temperature $\left(500^{\circ} \mathrm{C}\right)$, higher reduction in compressive strength is observed and this may be due to melting of the rubber particles and increasing porosity in the mortar specimens. Thermal decomposition of some binding products such as $\mathrm{Ca}-$ sulphate- aluminate hydrate and calcium silicate hydrates may also the reasons for the higher reduction in the compressive strength at high temperatures.

Figure 2 demonstrates the effect of GWTR \% on the relative compressive strength of mortar specimens at different high temperatures. The figure clearly indicates that the relative compressive strength increases with increasing GWTR up to $5 \%$ at some temperature and $10 \%$ others and after that it decreases at all temperatures. Thus we can conclude that the optimum GWTR \% for high temperatures applications under compression loads is ranged from $5 \%$ to $10 \%$.

To explain the effect of GWTR/TFA \% on the compressive strength of mortar, the strength of specimen exposed to high temperature and containing GWTR was divided by that of $100 \%$ sand and exposed to the same target temperature. This is defined as the compressive strength ratio. The effect of GWTR/TFA $\%$ on the strength ratio at different exposure temperature including room temperature is shown in Fig. 3. The same trend for all target temperature is observed, i.e. linear reduction in the strength ratio with increasing GWTR/TFA \%.

The data in the data figure best fit the following relation between the GWTR/TFA \% and the compressive strength ratio:

Strength ratio, $\%=100-2.13$ (GWTR/TFA \%)

At GWTR/TFA \% equal to zero, the compressive strength is the strength of $100 \%$ sand specimens. The above equation is valid up to GWTR/TFA \% equal to $46.95 \%$.

\subsection{Tensile Strength}

The tensile strength of GWTR mortar specimens shows similar trends as that of compression. The effect of high temperatures on the relative tensile strength of mortar specimens fabricated by partial replacement of sand by GWTR (GWTR/TFA $\%=0$, $5,10,15$ and $20 \%$ ) is shown in Fig. 4. The relative tensile strength showed in the figure is ratio multiplied by 100 of the strength of specimen exposed to high temperature to that of the unheated specimen at the same GWTR/TFA \%. It is clear that, all mortar mixes exposed to fire suffered a gradual decrease in the relative tensile strength with increasing high temperatures. 
M. Seleem, M. Balaha, H. Khalil, E. Zaki, "Effect of High Temperature on the Mechanical Strength of ..."
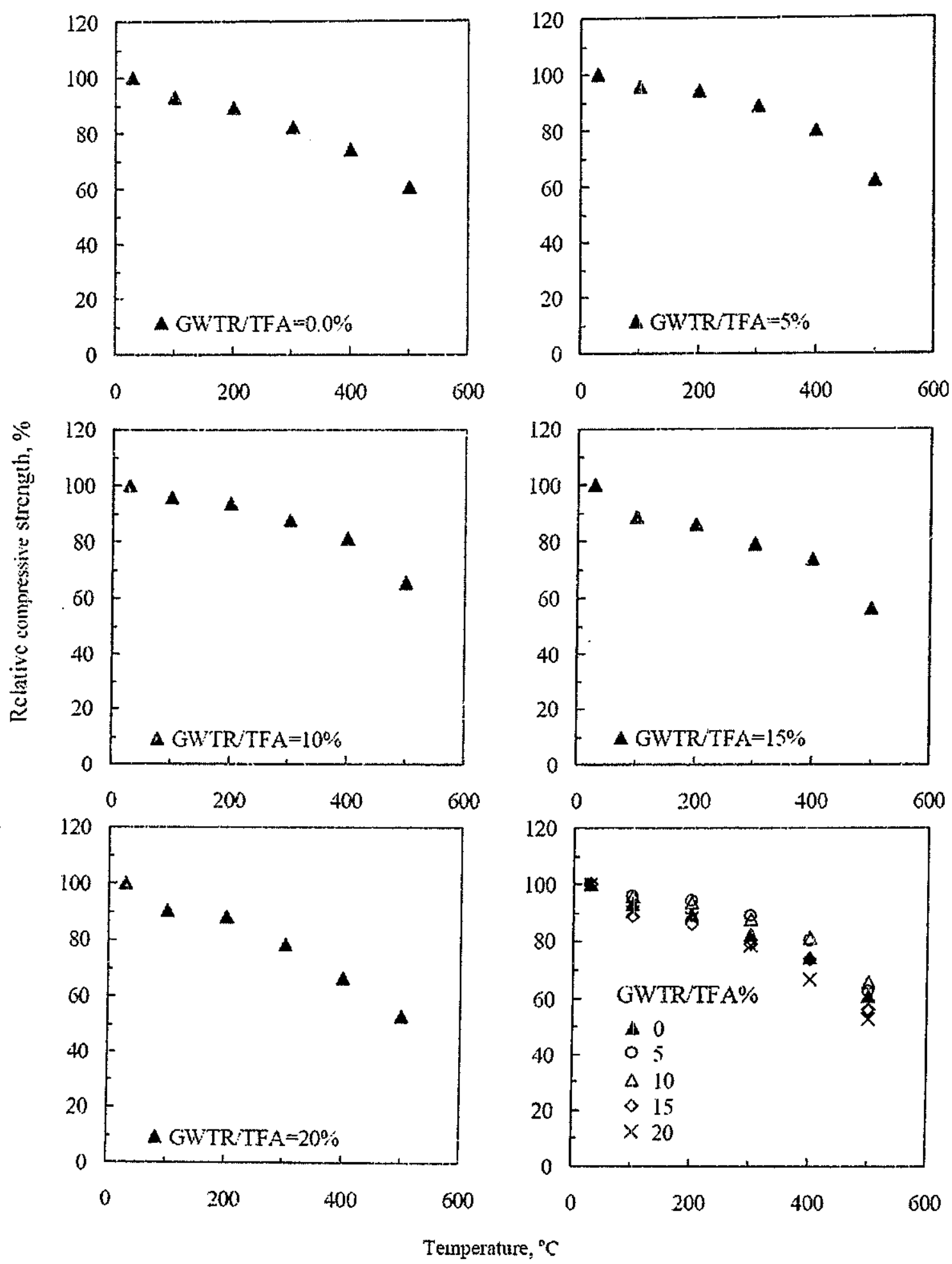

Fig. 1 Relative compressive strength against temperatures for different GWTR/TFA \%. 
The average relative strength for all GWTR/TFA \% was about $97,94,86.5,81.5$ and $64 \%$ for target temperatures of respectively $100,200,300,400$ and $500^{\circ} \mathrm{C}$. These average relative strengths are higher to some extent to those recorded under compression. This means that the degradation in the strength in the case of tensile stresses is smaller than that in the case of compressive stresses. This is expected due to the small resistance of rubber particles to compression load compared to its better resistance to tensile loads. The small gradual decrease in the tensile strength at low temperature may be due to the existence of rubber particles absorbs the volume change occurred in the specimens due to heating. At high temperature $\left(500^{\circ} \mathrm{C}\right)$, higher reduction in the tensile strength is observed and this may be due to melting of the rubber particles and increasing porosity in the mortar specimens. Thermal decomposition of some binding products such as $\mathrm{Ca}$-sulphate- aluminate hydrate and calcium silicate hydrates may also the reasons for the higher reduction in the tensile strength at high temperatures. Visual examination of specimen surfaces of GWTR mortar after exposure to high temperatures up to $\left(500^{\circ} \mathrm{C}\right)$ reveals no cracks appeared on such surface. This indicates that the presence of GWTR absorbed any volume changes in the matrix as a result of thermal expansion.

Figure 5 demonstrates the effect of GWTR \% on the relative tensile strength of mortar specimens at different high temperatures. The figure clearly indicates that the relative tensile strength increases with increasing GWTR up to $10 \%$ in some cases and up to $15 \%$ in other cases and after that it decreases at all temperatures. Thus we can conclude that the optimum GWTR \% for high temperatures applications under tensile loads is ranged between $10 \%$ and $15 \%$.

To explain the effect of GWTR/TFA \% on the tensile strength of mortar, the strength of specimen exposed to high temperature and containing GWTR was divided by that of $100 \%$ sand and exposed to the same target temperature. This is defined as the tensile strength ratio. The effect of GWTR/TFA \% on the tensile strength ratio at different exposure temperature including room temperature is shown in Fig. 6. The same trend for all target temperature is observed, i.e. linear reduction in the tensile strength ratio with increasing GWTR/TFA \%. The data in the data figure best fit the same relation in compression between the GWTR/TFA \% and the tensile strength ratio.

\subsection{Mass loss}

Heat induced mass losses due to water evaporation and melt of rubber for all mixtures are shown in Fig. 7. The mass loss illustrated in this figure represents the normalization of the difference in mass loss between the unheated and heated specimens to that of the unheated specimens multiplied by 100 . All mixtures demonstrated an increase in the mass loss percentage with increasing tempreture. These losses are increased with increasing GWTR to high temperature. The loss rate is low at the first stages of heating up to tempreature of $200^{\circ} \mathrm{C}$. When the heating temperature is under $200^{\circ} \mathrm{C}$, the mass loss is completely caused by quick evaporation of capillary water, and concrete undergoes a physical process. For a temperature between 200 and $400^{\circ} \mathrm{C}$, the weight loss is mainly caused by gradual evaporation of gel water and melt of rubber, and the concrete undergoes a mix physico-chemical process. For a temperature over $400^{\circ} \mathrm{C}$, the weight loss is mainly caused by the melt of rubber and evaporation of chemically combined water (dehydration) and decomposition, so the concrete undergoes a chemical process [10].

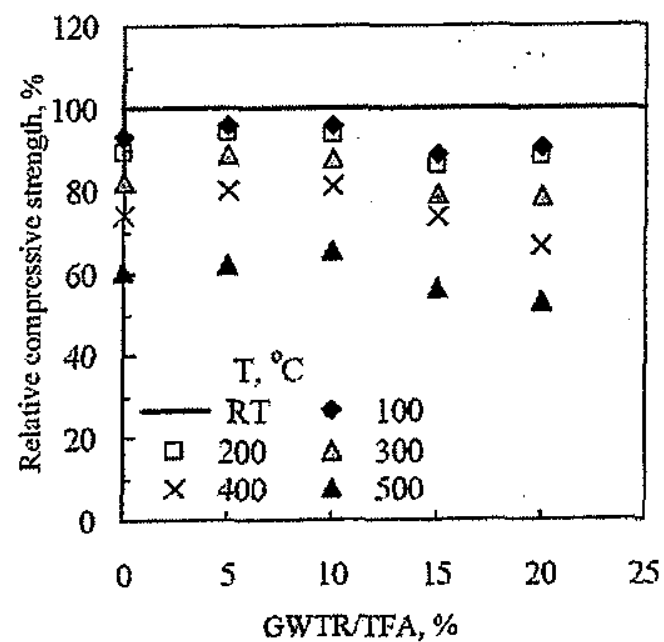

Fig.2 Effect of GWTR \% on the relative compressive strength

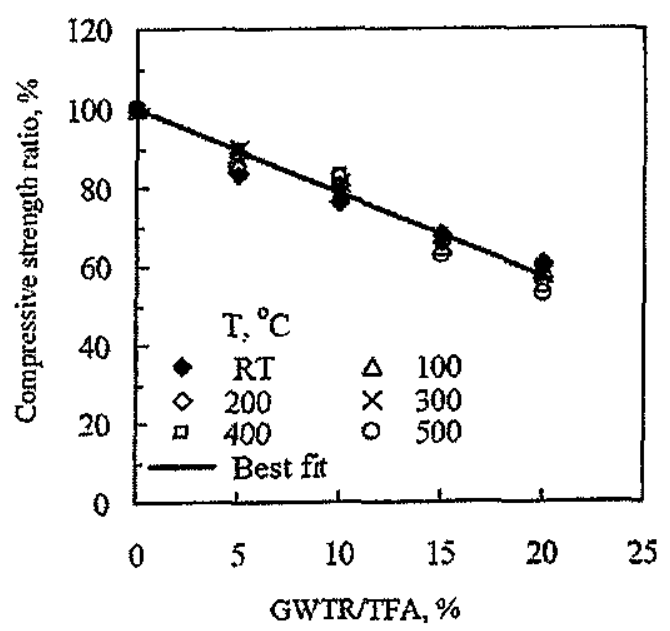

Fig. 3 Effect of GWTR \% on the compressive strength ratio 
M. Seleem, M. Balaha, H. Khalil, E. Zaki, "Effect of High Temperature on the Mechanical Strength of ..."
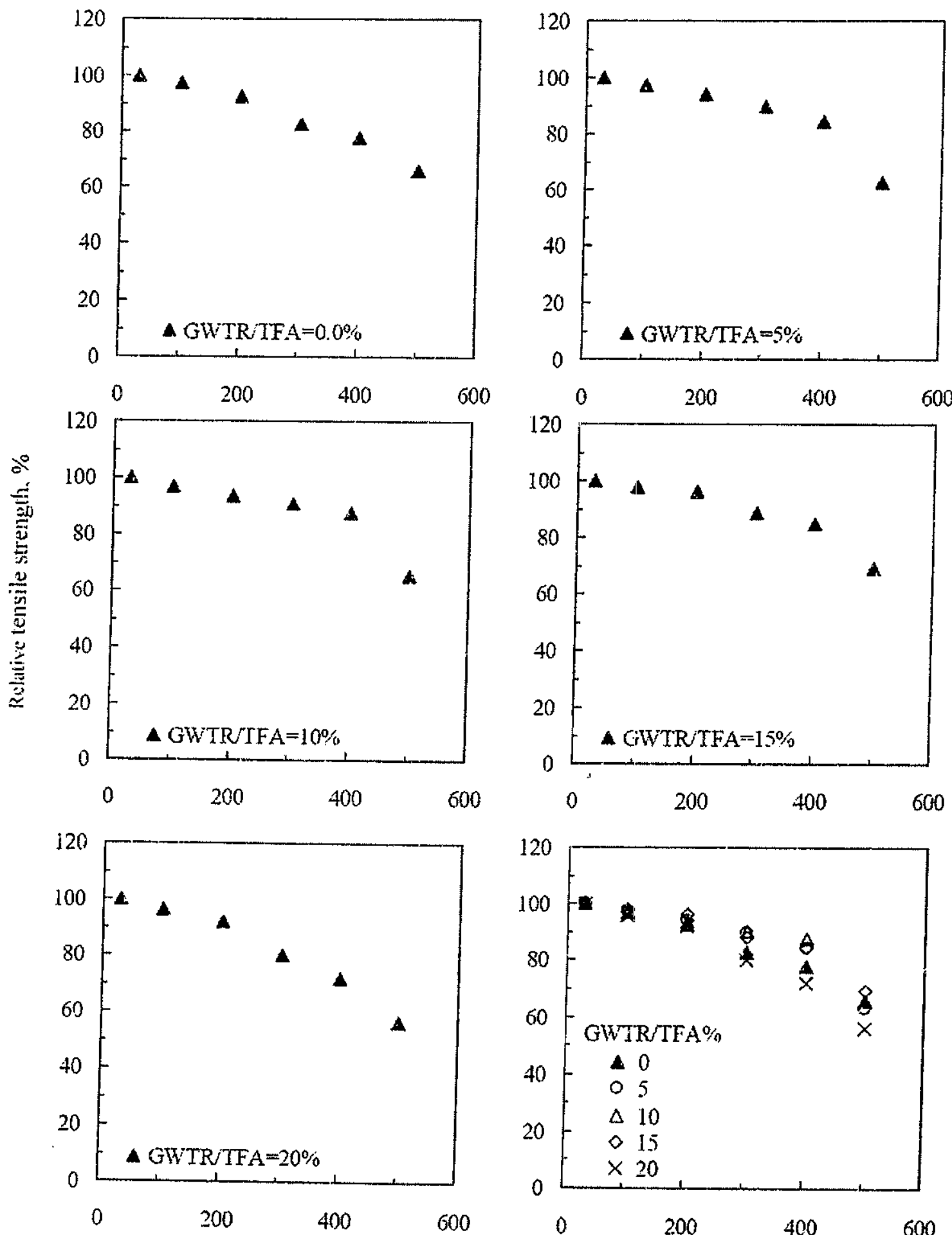

Tenperature, ${ }^{\circ} \mathrm{C}$

Fig. 4 Relative tensile strength against temperatures for different GWTR/TFA \%. 


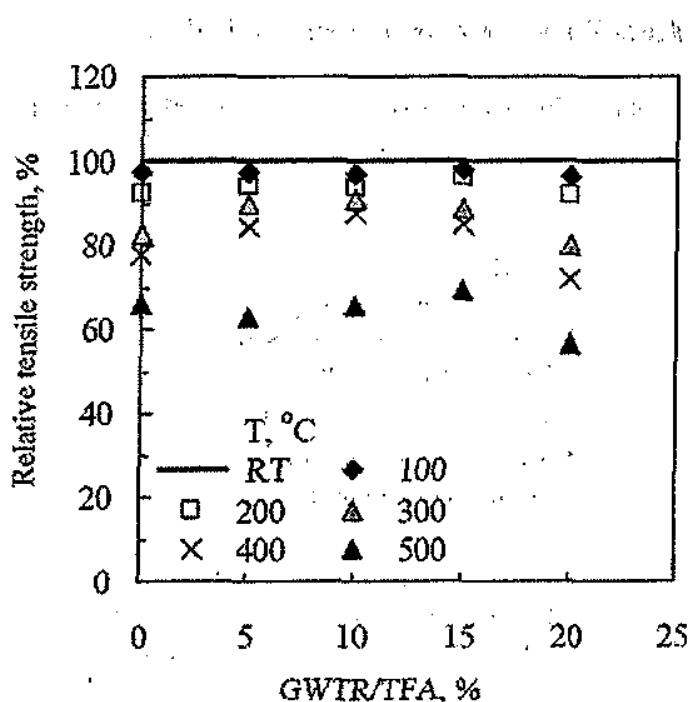

Fig.5 Effect of GWTR \% on the relative tensile strength

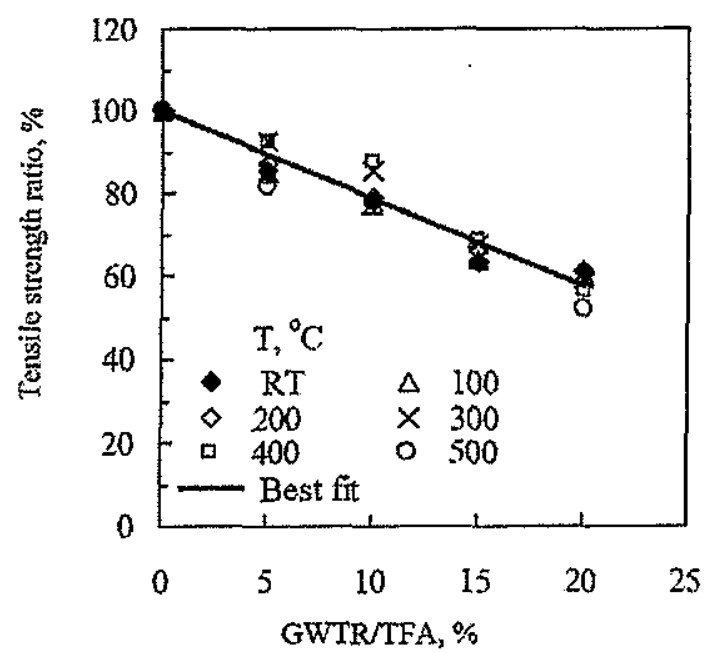

Fig.6 Effect of GWTR \% on the tensile strength ratio

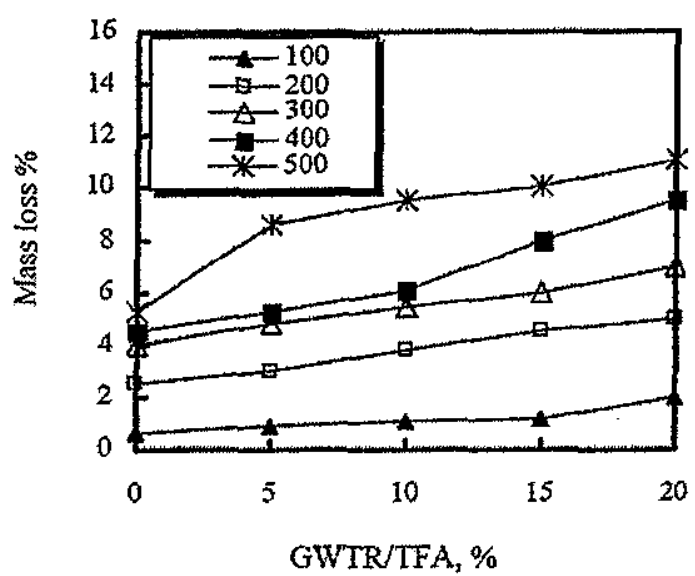

Fig.7 Effect of GWTR \% on mass loss percentage.

\section{CONCLUSIONS}

Based or 'the test results from this study the following conclusions could be drawn as follows:

1- All mortars specimens exposed to high temperatures showed a decrease in both compressive and tensile strengths with increasing temperature. The reduction in the compressive strength was higher than that recorded in tensile strength.

2- The GWTR/TFA \% showed remarkable effect on the mortars compressive and tensile strengths after their exposure to high temperature. Where, the compressive strength and tensile strengths of rubberized mortars decreased with increasing of GWTR/TFA \%.

3- The optimum GWTR $\%$, which gave the highest relative compressive strength, was in the range from $5 \%$ to $10 \%$, while that gave the highest relative tensile strength was in the range from $10 \%$ to $15 \%$.

4- A linear relation existed between the compressive strength ratio and the tensile strength ratio (ratio of the strength of rubberized mortar to that of $100 \%$ sand at specified temperature) and the GWTR \% at all temperatures considered.

5- The mass loss increased with increasing of temperature up to $5000 \mathrm{C}$ and GWTR $\%$.

\section{REFERENCES}

[1] Jang, J. w., T. Oh, J, and Iwasaki, I., (1998) "Discarded Tire Recycling Practices in the United States, Japan and Korea. Resources", Conservation and Recycling Vol. 22, pp. 1-14.

[2] Garrick G. M, (2005), "Analysis and Testing of Waste Tire Fiber Modified Concrete", M. Sc., Jamaica, Mechanical Engineering Dept., Louisiana State University.

[3] Cecich V, Gonzales L, Hoisaeter A, Williams J \& Reddy K R, (1994), Use of Shredded Tyres as a Lightweight Backfill Material for Retaining Structures, Report No. CE-GEE-94- 02, University of Illinois at Chicago, Chicago, Illinois, U.S.A.

[4] Humphrey D. N., Sandford, T. C., Cribbs, M. M. \& Manion, W. P., (1993), Shear Strength and Compressibility of Tire Chips for Use as Retaining Wall Backfill, Transportation Research Record 1422, Washington D.C., U.S.A.

[5] Jang J. W., Yoo T., Oh J. \& Iwasaki I., (1998) Japan-Korea. Resources, Conserv Recycle, Vol. 22, pp. 1-14. 
[6] Biel T. D. \& Lee H., (1994), Use of Recycled Tire Rubbers in Concrete, Proc ASCE $3^{\text {rd }}$ Materiais Engineering Conf, Infrastructure: New Materials and Methods of Repair, pp. 351-358.

[7] Humphrey, D. N., Eaton, R. A., (1993), Tire Chips as Subgrade Insulation-Field Trial, Symposium on Recovery and Effective Reuse of Discarded Materials and By-Products for Construction of Highway Facilities, Denver, Colorado, U.S.A.

[8] Upton, R. J., Machan, G., (1993), Use of Shredded Tires for Lightweight Fill, Transportation Research Record 1422, Washington, D.C., U.S.A.

[9] Humphrey, D. N., (1999), Civil Engineering Applications of Tire Shreds, Proc Tire Industry Conf, Clemson University, March 3-5, p 16.

[10] Lea, F. M., (1998), The Chemistry of Cement and Concrete, $4^{\text {th }}$ Edn, Arnold Pub. Group, London.
[11] Ramachandran, V. C., (1969), Application of Differential 'Themal Analysis in Cement Chemistry, Chemical Publishing Company, INC., New York.

[12] British Standard Institution, (1990), Specification for Light Weight Aggregate for Masonry Ünits and Structural Concrete, B.S. 3793, London, 1990.

[13] František škvàra and Vàclav ševèik, (1999) Influence of High Temperature on GF Portland Cement Materials, Cem Concr Res 29, pp. 713717.

[14] Balaha, M. M., Badawy, A. A. M and Hashish, M., (2007), "Effect of using ground waste tire rubber as fine aggregate on the behavior of concrete mixes", Indian Journal of Engineering \& Materials Sciences Vol. 14, December 2007, pp. $427-435$ 